\title{
Thermal Conversion of Guanylurea Dicyanamide into Graphitic Carbon Nitride via Prototype $\mathbf{C N}_{x}$ Precursors
}

\author{
Bettina V. Lotsch and Wolfgang Schnick* \\ Lehrstuhl für Anorganische Festkörperchemie, Department Chemie und Biochemie, \\ Ludwig-Maximilians-Universität München, Butenandtstrasse 5-13, D-81377 München, Germany
}

Received February 16, 2005. Revised Manuscript Received May 17, 2005

\begin{abstract}
Guanylurea dicyanamide, $\left[\left(\mathrm{H}_{2} \mathrm{~N}\right) \mathrm{C}(=\mathrm{O}) \mathrm{NHC}\left(\mathrm{NH}_{2}\right)_{2}\right]\left[\mathrm{N}(\mathrm{C} \equiv \mathrm{N})_{2}\right]$, has been synthesized by ion exchange reaction in aqueous solution and structurally characterized by single-crystal X-ray diffraction $(C 2 / c, a=$ 2249.0(5) pm, $b=483.9(1) \mathrm{pm}, c=1382.4(3) \mathrm{pm}, \beta=99.49(3)^{\circ}, V=1483.8(5) \times 10^{6} \mathrm{pm}^{3}, T=130$ $\mathrm{K})$. The thermal behavior of the molecular salt has been studied by thermal analysis, temperatureprogrammed X-ray powder diffraction, FTIR spectroscopy, and mass spectrometry between room temperature and $823 \mathrm{~K}$. The results were interpreted on a molecular level in terms of a sequence of thermally induced addition, cyclization, and elimination reactions. As a consequence, melamine $(2,4,6-$ triamino-1,3,5-triazine) is formed with concomitant loss of HNCO. Further condensation of melamine yields the prototypic $\mathrm{CN}_{x}$ precursor melem (2,6,10-triamino-s-heptazine, $\left.\mathrm{C}_{6} \mathrm{~N}_{7}\left(\mathrm{NH}_{2}\right)_{3}\right)$, which alongside varying amounts of directly formed $\mathrm{CN}_{x} \mathrm{H}_{y}$ material transforms into layered $\mathrm{CN}_{x} \mathrm{H}_{y}$ phases without significant integration of oxygen into the core framework owing to the evaporation of HNCO. Thus, further evidence can be added to melamine and its condensation product melem acting as "key intermediates" in the synthetic pathway toward graphitic $\mathrm{CN}_{x} \mathrm{H}_{y}$ materials, whose exact constitution is still a point at issue. Due to the characteristic formation process and hydrogen content a close relationship with the polymer melon is evident. In particular, the thermal transformation of guanylurea dicyanamide clearly demonstrates that the formation of volatile compounds such as $\mathrm{HNCO}$ during thermal decomposition may render a large variety of previously not considered molecular compounds suitable $\mathrm{CN}_{x}$ precursors despite the presence of oxygen in the starting material.
\end{abstract}

\section{Introduction}

Synthetic approaches toward condensed $\mathrm{CN}_{x}$ network materials have been an intensely pursued issue over the past decade. ${ }^{1-7}$ Although $\mathrm{sp}^{3}$-hybridized modifications of $\mathrm{C}_{3} \mathrm{~N}_{4}$, some of which are believed to be at the forefront of ultrahard materials, have not been synthesized as yet, the preparation of several layered modifications of $\mathrm{C}_{3} \mathrm{~N}_{4}$ has been claimed. A common feature of the latter phases, however, is the ubiquitous hydrogen content (up to about $2 \mathrm{wt} \%$ ), possibly rendering these structures oligo- or polymeric melon-type materials whose composition is frequently being expressed by $\left[\mathrm{C}_{6} \mathrm{~N}_{9} \mathrm{H}_{3}\right]_{n}$ in the literature $(1.5 \mathrm{wt} \%$ hydrogen $){ }^{8-12}$ Although many attempts have been undertaken to prepare pure carbon nitride phases of exact composition $\mathrm{C}_{3} \mathrm{~N}_{4}$ starting from a variety of precursors such as $\mathrm{NH}_{4} \mathrm{SCN}$, thiourea derivatives, or melamine, hydrogen could not completely be

* To whom correspondence should be addressed. E-mail: wolfgang.schnick@ uni-muenchen.de.

(1) Cohen, M. L. Phys. Rev. 1985, B32, 7988.

(2) Liu, A. Y.; Cohen, M. L. Science 1989, 245, 841

(3) Niu, C.; Lu, Y. Z.; Lieber, C. M. Science 1993, 261, 334.

(4) Teter, D. M.; Hemley, R. J. Science 1996, 271, 53.

(5) Mattesini, M.; Matar, S. F.; Snis, A.; Etourneau, J.; Mavromaras, A. J. Mater. Chem. 1999, 9, 3151.

(6) Kroke, E.; Schwarz, M. Coord. Chem. Rev. 2004, 248, 493.

(7) Kroll, P.; Hoffmann, R. J. Am. Chem. Soc. 1999, 121, 4696

(8) Liebig, J. v. Ann. Pharm. (Lemgo, Ger.) 1834, 10, 10.

(9) Gmelin, L. Ann. Pharm. (Lemgo, Ger.) 1835, 15, 252.

(10) Liebig, J. v. Ann. Chem. Pharm. 1850, 50, 337.

(11) Liebig, J. v. Ann. Chem. Pharm. 1850, 73, 257.

(12) Franklin, E. C. J. Am. Chem. Soc. 1922, 44, 486. eliminated without decomposing the structure-directing $\mathrm{CN}_{x}$ core. ${ }^{13-16}$ The latter $\mathrm{CN}_{x} \mathrm{H}_{y}$ phases, which are somewhat simplistically denoted as graphitic carbon nitride (" $\mathrm{g}-\mathrm{C}_{3} \mathrm{~N}_{4}$ "), have entered the focus as potential precursors for the highpressure synthesis of $\mathrm{sp}^{3}$-hybridized forms of $\mathrm{C}_{3} \mathrm{~N}_{4}$. Information about their exact stoichiometry and composition as well as their structural building units is however still sparse and rather speculative. ${ }^{17-24}$ Although the importance of reproducible and tailored synthesis strategies toward low-dimensional $\mathrm{CN}_{x}$ networks as well as their structural characterization is beyond controversy, little advertence has been attached to resolving the detailed mechanism of thermal condensation reactions of molecular precursors. However, to compile basic

(13) May, H. J. Appl. Chem. 1959, 340.

(14) Komatsu, T. Macromol. Chem. Phvs. 2001, 202, 19.

(15) Shtrempler, G. I.; Murzubraimov, B.; Rysmendeev, K. Russ. J. Inorg. Chem. 1982, 27, 442.

(16) Nurakhmetov, N. N.; Beremzhanov, B. A.; Tashenov, A.; Erkasov, R. S. Russ. J. Inorg. Chem. 1987, 32, 6.

(17) Alves, I.; Demazeau, G.; Tanguy, B.; Weill, F. Solid State Commun 1999, 109, 697

(18) Mattesini, M.; Matar, S. F.; Etourneau, J. J. Mater. Chem. 2000, 10, 709.

(19) Komatsu, T.; Nakamura, T. J. Mater. Chem. 2001, 11, 474

(20) Komatsu, T. J.Mater. Chem. 2001, 11, 799.

(21) Komatsu, T. J. Mater. Chem. 2001, 11, 802.

(22) Kroke, E.; Schwarz, M.; Horath-Bordon, E.; Kroll, P.; Noll, B.; Norman, A. D. New J. Chem. 2002, 26, 508.

(23) Jürgens, B.; Irran, E.; Senker, J.; Kroll, P.; Müller, H.; Schnick, W. J. Am. Chem. Soc. 2003, 125, 10288.

(24) Kouvetakis, J.; Bandari, A.; Todd, M.; Wilkens, B.; Cave, N. Chem. Mater. 1994, 6, 811. 
principles of thermal reaction pathways and to identify the smallest structural motifs of the resulting g- $\mathrm{C}_{3} \mathrm{~N}_{4}$ structures, a broad overview over different reaction types of various substrates, the formation of intermediates, and potential analogies between them is mandatory. In this context, we have been focusing on the study of the solid-state reactivity of molecular $\mathrm{CN}_{x}$ precursors such as dicyanamides and tricyanomelaminates, which are known to exhibit various types of thermally induced transformations. ${ }^{25-32}$ Ammonium dicyanamide has been used as a model system to elucidate mechanistic aspects such as structural and kinetic implications of the proton transfer involved in the isomerization into dicyandiamide..$^{25-27}$ Guanidinium dicyanamide was shown to transform into melamine, thereby following a transformation pattern analogous to that found for ammonium dicyanamide, though passing through the melt before cyclization. ${ }^{28}$ Hydrazinium dicyanamide was also reported to be thermally unstable with respect to cyclization, forming guanazole, $\mathrm{C}_{2} \mathrm{~N}_{5} \mathrm{H}_{5}$, in a strongly exothermic reaction at temperatures as low as $323 \mathrm{~K}^{33}$ The melaminium salt of dicyanamide, after undergoing a series of phase transitions between 343 and $533 \mathrm{~K}$, finally yields melamine and its condensation products, depending on the temperature, as the only detectable crystalline products.

The thermal reactivity of nonmetal tricyanomelaminate salts such as ammonium, $\left[\mathrm{NH}_{4}\right]_{2}\left[\mathrm{C}_{6} \mathrm{~N}_{9} \mathrm{H}\right]$, or guanidinium tricyanomelaminate, $\left[\mathrm{C}\left(\mathrm{NH}_{2}\right)_{3}\right]_{3}\left[\mathrm{C}_{6} \mathrm{~N}_{9}\right]$, which are being investigated presently in our group, seem to follow a complex decomposition pathway rather than undergoing condensation reactions which are directly driven by the reactive cyanamide moieties, effecting subsequent formation of the expected melamine-type $\mathrm{CN}_{x}$ networks. On the contrary, all tricyanomelaminates under investigation yielded melamine or, depending on the temperature, its transformation product melem, $\mathrm{C}_{6} \mathrm{~N}_{7}\left(\mathrm{NH}_{2}\right)_{3}$, as the final product. ${ }^{34}$ To extend the study of systems with potential thermal solid-state reactivity, another dicyanamide salt, guanylurea dicyanamide, was synthesized and its solid-phase transformation compared with previously observed reaction schemes of related systems. Though not being a pure $\mathrm{CN}_{x}$ compound, the suitability of guanylurea dicyanamide as a precursor was probed owing to the possibility of unexpected condensation pathways stimulated by the presence of oxygen in the starting material. The present study is thus intended to investigate the temperature response of the novel dicyanamide salt and to place it in the broader context of the observed thermal solidstate reactivity of molecular $\mathrm{CN}_{x}$ precursors.

(25) Jürgens, B.; Höppe, H. A.; Irran, E.; Schnick, W. Inorg. Chem. 2002, $41,4849$.

(26) Lotsch, B. V.; Senker, J.; Kockelmann, W.; Schnick, W. J. Solid State Chem. 2003, 176, 180

(27) Lotsch, B. V.; Senker, J.; Schnick, W. Inorg. Chem. 2004, 43, 895

(28) Lotsch, B. V.; Schnick, W. New J. Chem. 2004, 28, 1129.

(29) Jürgens, B.; Milius, W.; Morys, P.; Schnick, W. Z. Anorg. Allg. Chem. 1998, 624, 91.

(30) Jürgens, B.; Irran, E.; Schneider, J.; Schnick, W. Inorg. Chem. 2000, 39,665 .

(31) Irran, E.; Jürgens, B.; Schnick, W. Chem.-Eur. J. 2001, 7, 5372.

(32) Irran, E.; Jürgens, B.; Schnick, W. Solid State Sci. 2002, 4, 1305.

(33) Frankel, M. B.; Burns, E. A.; Butler, J. C.; Wilson, E. R. J. Org. Chem. 1963, 28, 2428.

(34) Lotsch, B. V.; Schnick, W. Unpublished results.

\section{Experimental Section}

Synthesis. Guanylurea dicyanamide was obtained by ion exchange reaction in aqueous solution. Thus, $225 \mathrm{~mL}$ of an aqueous solution of $4.42 \mathrm{~g}\left(14.6 \times 10^{-3} \mathrm{~mol}\right)$ of guanylurea sulfate (Acros Organics, $98 \%$ ), which was slightly heated for complete dissolution of the salt, was poured onto a column containing $6 \mathrm{~mL}$ (ion exchange capacity $10.2 \times 10^{-3} \mathrm{~mol}$ ) of a strongly acidic ionexchange resin (Merck, Ionenaustauscher $\mathrm{I} \mathrm{H}^{+}$-Form, Art. 4765). Full loading was indicated by the change from acidic $\left(\mathrm{H}_{2} \mathrm{SO}_{4}\right)$ to neutral $\mathrm{pH}$ of the eluate, corresponding to that of a solution of guanylurea sulfate. After the column was thoroughly washed with $3 \mathrm{~L}$ of deionized water, $0.420 \mathrm{~g}\left(4.7 \times 10^{-3} \mathrm{~mol}\right)$ of sodium dicyanamide ( $\geq 96 \%$, Fluka) in $10 \mathrm{~mL}$ of $\mathrm{H}_{2} \mathrm{O}$ was poured onto the column. The eluate was collected and crystallized by evaporation of the solvent. When traces of the starting material sodium dicyanamide were found in the product, the ion exchange procedure was repeated.

Evidence was found for the formation of a metastable phase of guanylurea dicyanamide, whose chemical identity was probed by its vibrational spectra. Since upon recrystallization from aqueous solution or storing the sample in air for a couple of days the metastable modification transformed into that reported in this study, no crystals suitable for single-crystal X-ray analysis could be obtained as yet.

${ }^{1} \mathrm{H}$ NMR (400.0 MHz, DMSO- $\left.d_{6}\right): \delta=7.1(\mathrm{~s}, 2 \mathrm{H}, \mathrm{C}(=\mathrm{O})-$ $\left.\mathrm{NH}_{2}\right), 8.1\left(\mathrm{~s}, 4 \mathrm{H}, \mathrm{C}\left(=\mathrm{N} H_{2}\right)^{+} \mathrm{N} H_{2}\right), 10.0(\mathrm{~s}, 1 \mathrm{H}, \mathrm{N} H) .{ }^{13} \mathrm{C}\left\{{ }^{1} \mathrm{H}\right\} \mathrm{NMR}$ $\left(100.5 \mathrm{MHz}, \mathrm{DMSO}-d_{6}\right): \delta=155.2,156.1\left(C=\mathrm{O} / C=\mathrm{NH}_{2}{ }^{+}\right), 119.2$ $(C \equiv \mathrm{N}) . \mathrm{MS}\left(\mathrm{FAB}^{-}, 6 \mathrm{kV}\right): \mathrm{m} / z$ (rel intens $)=103.1(100)$ $\left[\mathrm{H}_{2} \mathrm{NC}(=\mathrm{O}) \mathrm{NHC}\left(=\mathrm{NH}_{2}\right) \mathrm{NH}_{2}\right]^{+}$.

General Methods. ${ }^{1} \mathrm{H}$ and ${ }^{13} \mathrm{C}$ NMR spectra were recorded as DMSO- $d_{6}$ solutions on a JEOL Eclipse EX-400 instrument, the chemical shifts being referenced with respect to the peak for TMS.

Mass spectra were obtained using a JEOL MStation JMS-700 gas inlet system. The substance was dissolved in a 3-nitrobenzyl alcohol matrix $\left(\mathrm{FAB}^{+}\right)$on a target and ionized by bombardment with accelerated $(6 \mathrm{kV}) \mathrm{Xe}$ atoms. Temperature-dependent direct insertion probes were recorded using $\mathrm{DEI}^{+}(70 \mathrm{eV})$ with the sample contained in an evacuated $\left(10^{-4}\right.$ mbar) Schlenk tube (length 330 $\mathrm{mm}, \varnothing=10 \mathrm{~mm}$ ) connected with the gas inlet system of the spectrometer via glass tubes of about $200 \mathrm{~mm}$ total length, thus providing dynamic vacuum conditions. The Schlenk tube was placed horizontally in a Carbolite furnace equipped with a 2132 Eurotherm temperature controller. The sample was heated to $493 \mathrm{~K}$ in steps of $1 \mathrm{~K} \mathrm{~min}-1$, and mass spectra of the volatile decomposition products were acquired successively at intervals of $2-5 \mathrm{~K}$.

Elemental analyses were performed using the commercial $\mathrm{C}, \mathrm{H}$, $\mathrm{N}$ elemental analyzer system Vario EL (Elementar Analysensysteme $\mathrm{GmbH})$.

Vibrational Spectroscopy. FTIR and Raman measurements were both carried out on a Bruker IFS 66v/S spectrometer after the respective measurement geometry was adjusted. IR spectra were recorded of samples prepared as $\mathrm{KBr}$ pellets ( $5 \mathrm{mg}$ of sample, 500 $\mathrm{mg}$ of $\mathrm{KBr}$ ) at ambient conditions in a range from 400 to 4000 $\mathrm{cm}^{-1}$. Raman spectra of the neat solids were acquired between 0 and $3600 \mathrm{~cm}^{-1}$ (Stokes lines).

Temperature-dependent FTIR measurements were conducted between 450 and $4000 \mathrm{~cm}^{-1}$ on a Perkin-Elmer IR Spectrum One spectrometer using a glass cell (volume approximately $50 \mathrm{~mL}$ ) closed at each side with $\mathrm{KBr}$ windows $(\varnothing=15 \mathrm{~mm})$ to detect the gas spectra under static vacuum. A $15 \mathrm{mg}$ portion of the solid sample was filled into the tubular elongation of the gas cell, which was evacuated $\left(1 \times 10^{-2} \mathrm{mbar}\right)$ and subsequently closed by Young valves, and then heated to $743 \mathrm{~K}$ by means of a Carbolite furnace equipped with a 2132 Eurotherm temperature controller. 


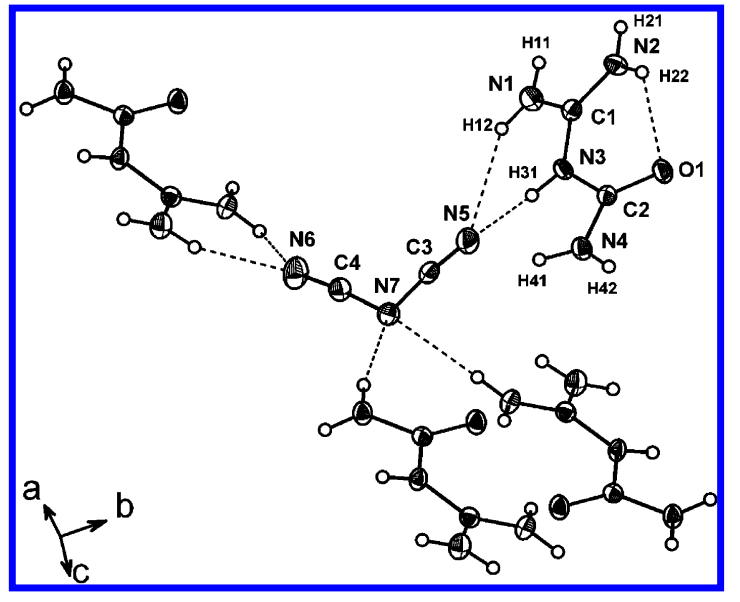

Figure 1. Coordination sphere of the dicyanamide ion and hydrogen bonding to neighboring guanylurea cations (dotted lines). The displacement ellipsoids are drawn at the $50 \%$ probability level.

X-ray Diffraction. X-ray diffraction data of a guanylurea dicyanamide single crystal (CCDC 275277) were recorded at 130 $\mathrm{K}$ on a STOE IPDS diffractometer using graphite-monochromated Mo $K \alpha$ radiation $(\lambda=71.073 \mathrm{pm})$. The crystal structure was solved by direct methods using the program SHELXS- $97^{35}$ and refined on $F^{2}$ by applying the full-matrix least-squares method implemented in SHELXTL-97. ${ }^{36}$ No absorption correction was carried out due to the weak absorption coefficients of the constituent atoms. The positions of all hydrogen atoms could be determined unequivocally from difference Fourier syntheses, and all non-hydrogen atoms were refined anisotropically.

High-temperature in situ X-ray diffractometry was performed on a STOE Stadi P powder diffractometer (Ge(111)-monochromated Mo $\mathrm{K} \alpha 1$ radiation, $\lambda=70.093 \mathrm{pm}$ ) with an integrated furnace, using unsealed quartz capillaries $(\varnothing=0.5 \mathrm{~mm})$ as sample containers. The data collection was restricted to a $2 \theta$ range of $5-18^{\circ}$ and a single scan collection time of $20 \mathrm{~min}$. The sample was heated from 303 to $823 \mathrm{~K}$ in steps of $5 \mathrm{~K} \mathrm{~min}^{-1}$, using a heating rate of $50 \mathrm{~K} \mathrm{~min}^{-1}$.

Thermal Analysis. Thermoanalytical measurements between room temperature and $823 \mathrm{~K}$ were conducted on a Mettler DSC 25 applying a heating rate of $1 \mathrm{~K} \mathrm{~min}^{-1}$. The aluminum crucible used as sample container was placed in the calorimeter under an atmosphere of dry nitrogen. Additionally, the thermal behavior of guanylurea dicyanamide was studied by heating samples contained in sealed glass ampules to temperatures around $723 \mathrm{~K}$. The products were analyzed by X-ray powder diffraction.

\section{Results}

Crystal Structure. Guanylurea dicyanamide, $\left[\left(\mathrm{H}_{2} \mathrm{~N}\right) \mathrm{C}\right.$ $\left.(=\mathrm{O}) \mathrm{NHC}\left(\mathrm{NH}_{2}\right)_{2}\right]\left[\mathrm{N}(\mathrm{C} \equiv \mathrm{N})_{2}\right]$, crystallizes in the space group $C 2 / c$ with eight formula units in the unit cell. Both anions and cations are loosely embedded in a hydrogen-bonding network consisting of medium strong and weak hydrogen bonds with $\mathrm{H} \cdots \mathrm{N} / \mathrm{O}$ contacts between 209 and $249 \mathrm{pm}$. The first "coordination sphere" of the cations consists of three guanylurea and four dicyanamide ions, while the anions are surrounded solely by cations (Figure 1). In the latter case, both bridging and terminal nitrogen atoms of the anion are involved in one medium strong and one weaker hydrogen

(35) Sheldrick, G. M. SHELXS-97, Program for the Solution of Crystal Structures; University of Göttingen: Göttingen, Germany, 1997.

(36) Sheldrick, G. M. SHELXS-97, Program for the Refinement of Crystal Structures; University of Göttingen: Göttingen, Germany, 1997.
Table 1. Crystal Data and Structure Refinement of $\left[\mathrm{H}_{2} \mathrm{NC}(=\mathrm{O}) \mathrm{NHC}\left(\mathrm{NH}_{2}\right) \mathrm{NH}_{2}\right]\left[\mathrm{N}(\mathrm{CN})_{2}\right]$

\begin{tabular}{|c|c|}
\hline empirical formula & $\mathrm{C}_{4} \mathrm{H}_{7} \mathrm{~N}_{7} \mathrm{O}$ \\
\hline molar mass $\left(\mathrm{g} \cdot \mathrm{mol}^{-1}\right)$ & 169.17 \\
\hline cryst syst & monoclinic \\
\hline space group & $C 2 / c$ (No. 15) \\
\hline temp $(\mathrm{K})$ & 130 \\
\hline diffractometer, monochromator & STOE IPDS, graphite \\
\hline radiation, $\lambda(\mathrm{pm})$ & Mo $\mathrm{K} \alpha, 71.073$ \\
\hline Z & 8 \\
\hline unit cell dimens (pm) & $\begin{array}{l}a=2249.0(5), b=483.9(1), \\
\quad c=1382.4(3)\end{array}$ \\
\hline$\beta(\operatorname{deg})$ & $99.49(3)$ \\
\hline $\operatorname{vol}\left(10^{6} \mathrm{pm}^{3}\right)$ & $1483.8(5)$ \\
\hline density $_{\text {calcd }}\left(\mathrm{g} \cdot \mathrm{cm}^{-3}\right)$ & 1.514 \\
\hline cryst size $\left(\mathrm{mm}^{3}\right)$ & $0.203 \times 0.155 \times 0.095$ \\
\hline $\mathrm{abs}$ coeff $\left(\mathrm{mm}^{-1}\right)$ & 0.119 \\
\hline$F(000)$ & 704 \\
\hline diffraction range (deg) & $2.99 \leq \theta \leq 30.50$ \\
\hline index range & $\begin{array}{l}-32 \leq h \leq+32,-6 \leq k \leq+6 \\
\quad-19 \leq l \leq+19\end{array}$ \\
\hline total no. of reflns & 8419 \\
\hline no. of independent reflns & $2170\left(R_{\mathrm{int}}=0.0581\right)$ \\
\hline no. of obsd reflns & 1496 \\
\hline $\begin{array}{l}\text { no. of refined params/ } \\
\text { constraints }\end{array}$ & $137 / 0$ \\
\hline corrections & Lorentz, polarization \\
\hline GOF on $F^{2}$ & 0.910 \\
\hline final $R$ indices $[I>2 \sigma(I)]$ & $\begin{array}{l}\mathrm{R} 1=0.0352 \\
\mathrm{wR} 2=0.0758\end{array}$ \\
\hline$R$ indices (all data) & $\begin{array}{l}\mathrm{R} 1=0.0617 \\
\mathrm{wR} 2=0.0826 \\
\text { with } w=\left[\sigma^{2}\left(F_{\mathrm{o}}^{2}\right)+(0.0453 P)^{2}+\right. \\
\quad 0.0000 P]^{-1}, \text { where } P=\left(F_{\mathrm{o}}^{2}+2 F_{\mathrm{c}}^{2}\right) / 3\end{array}$ \\
\hline $\begin{array}{c}\min / \text { max residual electron } \\
\text { density }\left(\mathrm{e} \cdot 10^{-6} \mathrm{pm}^{-3}\right)\end{array}$ & $-0.201 /+0.202$ \\
\hline
\end{tabular}

bridge each. Details of the crystal structure determination and refinement for guanylurea dicyanamide are listed in Table 1.

The deviation of the molecular geometry of the protonated guanylurea species from planarity is more pronounced than in the other structurally characterized guanylurea salts: ${ }^{37-39}$ The guanyl fragment is twisted about $11^{\circ}$ relative to the plane of the urea portion, which may be due to packing effects in the solid state. Despite the nonplanar arrangement, an intramolecular chelate-like hydrogen bond, $\mathrm{O} 1 \cdots \mathrm{H} 22-\mathrm{N} 2$, is formed. The $\mathrm{C}-\mathrm{N}$ distances of the guanidinium fragment are similar $(\mathrm{N} 2-\mathrm{C} 1=131.4 \mathrm{pm}$ and $\mathrm{N} 1-\mathrm{C} 1=132.4 \mathrm{pm})$, indicating significant delocalization of the double bond over the involved guanyl backbone. The distances found for the urea fragment $(\mathrm{O} 1-\mathrm{C} 2=122.7 \mathrm{pm}, \mathrm{N} 4-\mathrm{C} 2=133.4 \mathrm{pm})$ also suggest at least partial resonance within the $\mathrm{N}-\mathrm{C}-\mathrm{O}$ portion. The bond distances of the inner $\mathrm{C} 1-\mathrm{N} 3-\mathrm{C} 2$ fragment are close to those observed for $\mathrm{C}-\mathrm{N}$ single bonds (136.3 and $140.4 \mathrm{pm}$ ).

The molecular ions are stacked alternately in chains along [100], forming hydrogen bonds both within a chain and to adjacent chains running parallel (Figure 2), thus building up a loosely packed quasi two-dimensional network.

Spectroscopic Characterization. Guanylurea dicyanamide can easily be identified by its ${ }^{13} \mathrm{C}$ NMR spectrum, which in DMSO- $d_{6}$ solution exhibits characteristic signals

(37) Begley, M. J.; Hubberstey, P.; Martindale, S. P.; Moore, C. H. M.; Price, N. S. J. Chem. Res. 1988, 2, 101.

(38) Bremner, C. A.; Harrison, W. T. A. Acta Crvstallogr. 2002, E58, m254.

(39) Harrison, W. T. A.; Rodgers, J. A.; Phillips, M. L. F.; Nenoff, T. M. Solid State Sci. 2002, 4, 969 


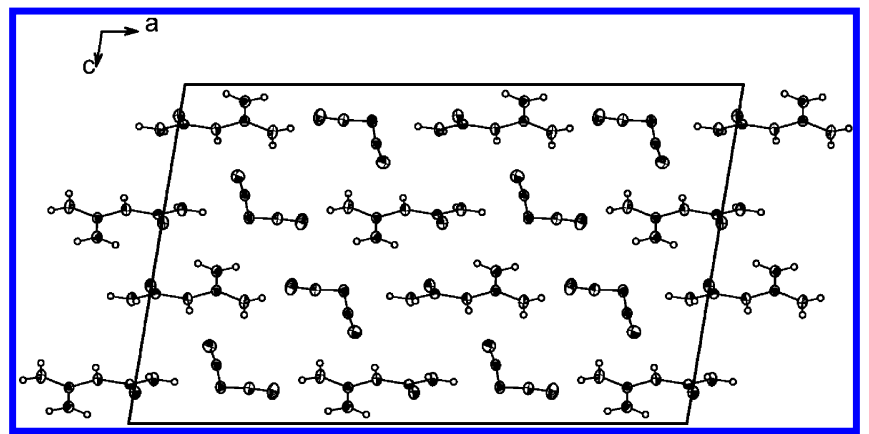

Figure 2. Unit cell of guanylurea dicyanamide, view along [010] onto the chains composed of alternating ions running along [100]. The displacement ellipsoids are drawn at the $50 \%$ probability level.

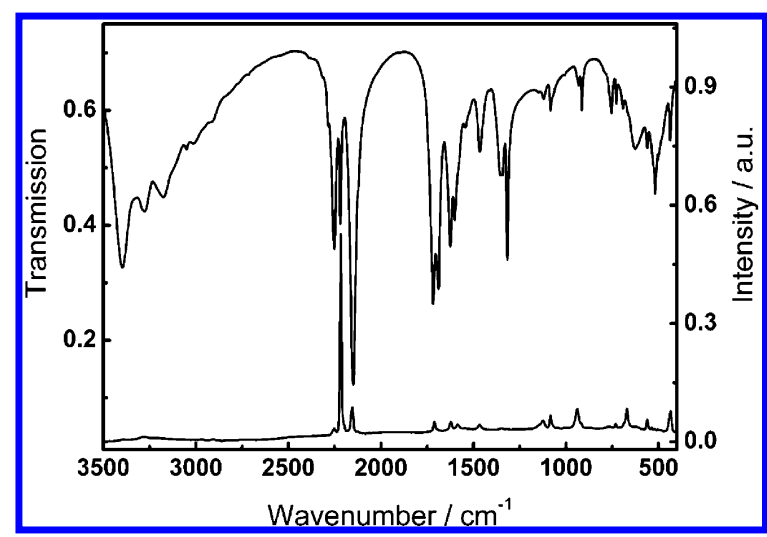

Figure 3. FTIR (top, left axis) and Raman (bottom, right axis) spectra of guanylurea dicyanamide, recorded between 3500 and $400 \mathrm{~cm}^{-1}$ at room temperature.

of $\mathrm{sp}^{2}$-hybridized carbon at 155.2 and $156.1 \mathrm{ppm}$, as well as a weaker signal at $119.2 \mathrm{ppm}$, indicating the presence of a nitrile group. The ${ }^{1} \mathrm{H}$ spectrum is less meaningful, since the three signals found at 7.1 (amide $\left.\mathrm{NH}_{2}\right), 8.1\left(2 \mathrm{NH}_{2}\right.$, guanidine moiety), and $10.0(\mathrm{NH}) \mathrm{ppm}$ are broadened owing to rapid exchange of the protons at room temperature.

Mass spectra acquired in the $\mathrm{FAB}^{+}$mode also give strong evidence for the saltlike character of the title compound by indicating the presence of guanylurea cations with $\mathrm{m} / \mathrm{z}=$ 103 (100).

The vibrational spectra of guanylurea dicyanamide are characterized by the typical dicyanamide triplet in the $v_{\text {s/as }}(\mathrm{C} \equiv \mathrm{N})$ region at $2252(\mathrm{~m}), 2219(\mathrm{~m})$, and $2150(\mathrm{~s}) \mathrm{cm}^{-1}$, which can rudimentarily be observed with reversed intensity distribution in the Raman spectrum at 2252 (w), 2217 (s), and $2154(\mathrm{~m}) \mathrm{cm}^{-1}$ (Figure 3). Strong absorption due to the cation is found in the $\mathrm{C}=\mathrm{N}$ stretching and $\mathrm{N}-\mathrm{H}$ bending region between 1450 and $1700 \mathrm{~cm}^{-1}$, as well as for the $\mathrm{C}=\mathrm{O}$ oxygen giving rise to a sharp band at $1717 \mathrm{~cm}^{-1}$. Typical dicyanamide bands are located at $1317\left(v_{\text {as }}(\mathrm{C}-\mathrm{N})\right)$, $914\left(v_{\mathrm{s}}(\mathrm{C}-\mathrm{N})\right), 518\left(\gamma_{\text {as }}(\mathrm{N}-\mathrm{C} \equiv \mathrm{N})\right)$, and $501\left(\delta_{\mathrm{as}}(\mathrm{N}-\mathrm{C} \equiv\right.$ N)) $\mathrm{cm}^{-1} \cdot{ }^{40,41}$

Thermal Behavior. Thermal Analysis. DSC measurements recorded with a heating rate of $1 \mathrm{~K} \mathrm{~min}^{-1}$ reveal a pronounced exothermic event around $390 \mathrm{~K}$, which is preceded by an endothermic "spike" in the baseline (Figure 4). At $430 \mathrm{~K}$ a broad, though less exothermic, signal is

(40) Jürgens, B.; Höppe, H. A.; Schnick, W. Solid State Sci. 2002, 4, 821. (41) Jürgens, B.; Irran, E.; Schnick, W. J. Solid State Chem. 2001, 157, 241.

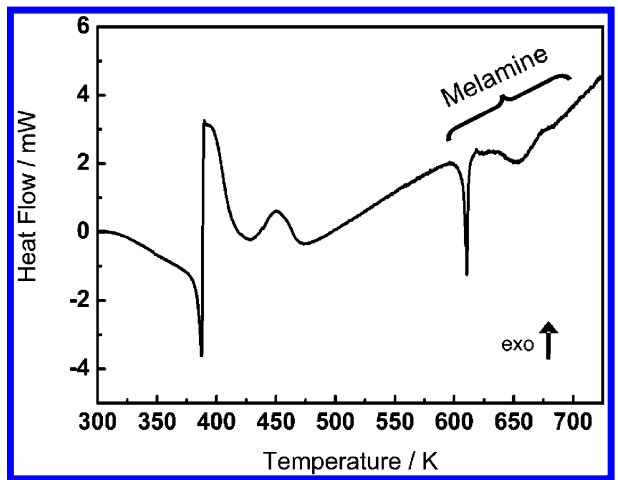

Figure 4. DSC heating curve of guanylurea dicyanamide recorded between 300 and $740 \mathrm{~K}$ with a heating rate of $1 \mathrm{~K} \mathrm{~min}^{-1}$.

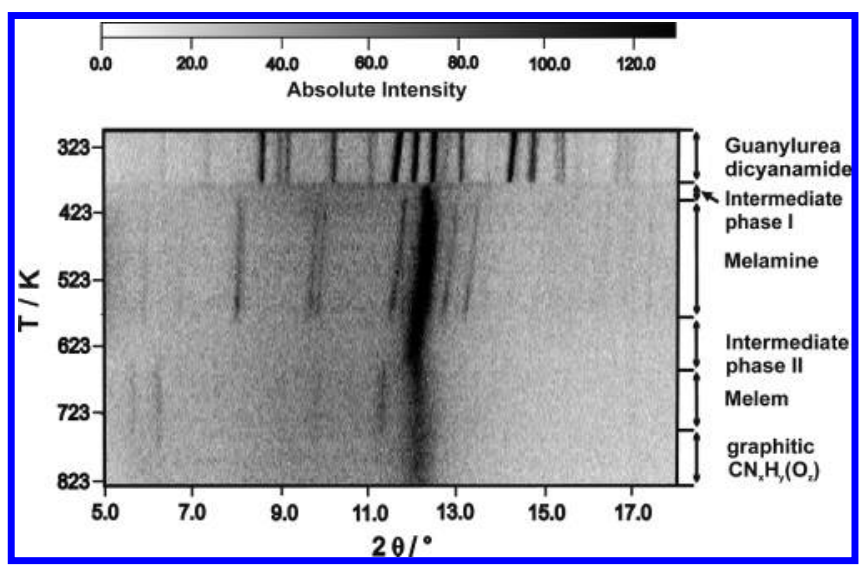

Figure 5. Variable-temperature X-ray powder diffraction patterns of guanylurea dicyanamide recorded in a $2 \theta$ range from $5^{\circ}$ to $18^{\circ}$ between 303 and 823 K. Starting material, intermediate phases, and products are indicated at the right margin.

observed, which is followed by an endothermic process around $610 \mathrm{~K}$ and another broad endothermic event with an onset around $635 \mathrm{~K}$.

A first hint at the nature of the processes observed is the resemblance of the high-temperature part of the DSC curve with that of melamine, which decomposes at $620 \mathrm{~K}$ and transforms into melem around $660 \mathrm{~K} .{ }^{23,42}$ Thus, the formation of melamine, presumably following a two-step process, may be considered further as a working hypothesis.

Temperature-Dependent X-ray Powder Diffraction. Temperature-programmed X-ray powder patterns collected at intervals of $5 \mathrm{~K}$ show a clear break at $378 \mathrm{~K}$, after which the sample temporarily passes through an essentially X-ray amorphous state (Figure 5). Regarding however the single powder patterns collected between 378 and $405 \mathrm{~K}$, a weak reflection at $2 \theta=12.4^{\circ}$ can be observed, suggesting a small degree of long-range order to be retained in this temperature range. Around $405 \mathrm{~K}$, a crystalline phase emerges, which can easily be identified as melamine. ${ }^{42}$ At $585 \mathrm{~K}$, the reflections largely disappear, leaving a single broad peak around $2 \theta \approx 12^{\circ}$, corresponding to $d \approx 340 \mathrm{pm}$, which may be assigned to an intermediate phase being discussed as a yet unidentified prestage of melem. ${ }^{42}$ At $650 \mathrm{~K}$, low-intensity reflections of melem ${ }^{23,42}$ can be observed, which disappear around $760 \mathrm{~K}$, yielding a graphitic $\mathrm{CN}_{x}$ material with an approximate $d$ spacing of $340 \mathrm{pm} .{ }^{6,17,19-21}$

(42) Jürgens, B. Ph.D. Thesis, University of Munich, Shaker Verlag: Aachen, Germany, 2004. 


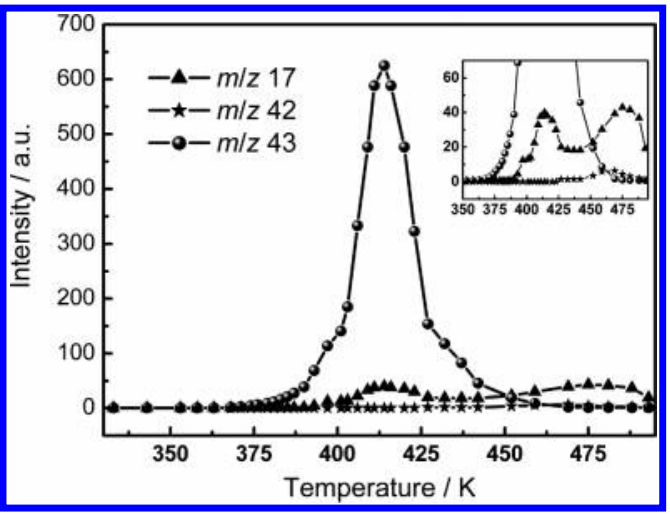

Figure 6. $m / z$ curves for the most significant mass peaks obtained by thermal decomposition of guanylurea dicyanamide while conducting temperature-dependent DEI mass spectrometry between 313 and $493 \mathrm{~K}$. Heating rates for $T \leq 348 \mathrm{~K}$ and $T>348 \mathrm{~K}$ were 2 and $1 \mathrm{~K} \mathrm{~min}^{-1}$, respectively. The temperature range between 350 and $493 \mathrm{~K}$ is displayed enlarged in the inset.

The above observations clearly indicate that melamine is formed without passing through crystalline intermediates detectable by X-ray powder diffraction. Slight discrepancies of the respective onset temperatures found for the complementary analytical methods are a trivial consequence of the different heating and pressure conditions. The stepwise character of the transformation as observed in the DSC measurements is however not detectable by $\mathrm{X}$-ray powder diffraction. Since the collection time for a single scan amounts to $20 \mathrm{~min}$, events that appear on a shorter time scale such as the formation of short-lived intermediates may not be accessible by this technique. Furthermore, low crystallinity of the intermediate phases may further deteriorate their observability and differentiation.

Temperature-Dependent Mass Spectrometry. To detect volatile species being potentially evolved during the observed transformation of the title compound, mass spectra were acquired while an evacuated sample of guanylurea dicyanamide was heated in a furnace up to $493 \mathrm{~K}$. Since no significant thermal event was expected up to about $353 \mathrm{~K}$, a heating rate of $2 \mathrm{~K} \mathrm{~min}^{-1}$ was applied until $348 \mathrm{~K}$. Subsequently, the sample was heated at $1 \mathrm{~K} \mathrm{~min}^{-1}$. Until $365 \mathrm{~K}$, a peak of relatively low intensity with $\mathrm{m} / z=18$ dominates the spectra, which can be attributed to water adsorbed on the sample and adhering to the inside wall of the spectrometer and glass tube. At $333 \mathrm{~K}$, a peak at $\mathrm{m} / \mathrm{z}=$ 43 appears, which rapidly grows and by $369 \mathrm{~K}$ dominates the spectra (Figure 6). In view of the potential decomposition pathways of the title compound as will be discussed in the following sections, this peak can be attributed to isocyanic acid, HNCO. Ammonia $(\mathrm{m} / \mathrm{z}=17)$ simultaneously appears, the associated intensity however being orders of magnitude smaller as compared to that of HNCO. The maximum intensity of the latter is reached around $411 \mathrm{~K}$, and commences to drop continuously until $440 \mathrm{~K}$. Here again, the peak at $m / z=17$, together with a low-intensity peak at $\mathrm{m} / \mathrm{z}=42$, steadily increases as shown in the inset of Figure 6. The maximum of the peak at $\mathrm{m} / \mathrm{z}=42$, which may indicate the presence of small amounts of cyanamide, $\mathrm{H}_{2-}$ $\mathrm{NC} \equiv \mathrm{N}$, is shifted to lower temperatures with respect to the maximum intensity of $\mathrm{m} / \mathrm{z}=17$, indicating two different underlying processes, which are at least partly decoupled

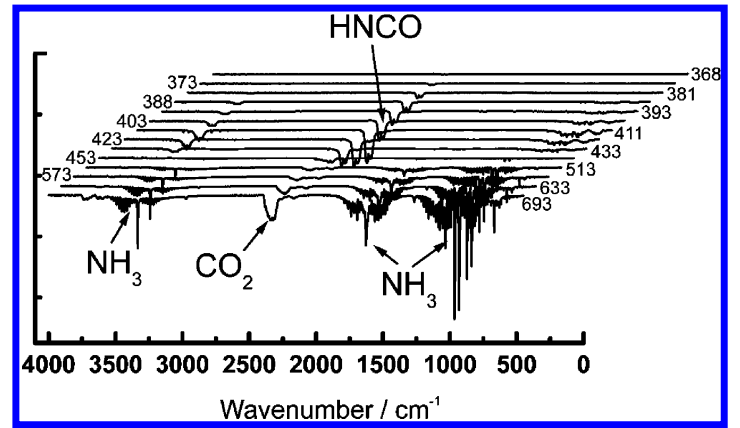

Figure 7. Temperature-dependent FTIR gas spectra collected between 368 and $693 \mathrm{~K}$ (back to front). The peak assignments are indicated by arrows; rotational sidebands are visible for $\mathrm{NH}_{3}$.

from each other. Beyond $450 \mathrm{~K}$ ammonia is the prevailing species in the system, while the peak at $\mathrm{m} / \mathrm{z}=43$ is hardly detectable by $470 \mathrm{~K}$. From a local maximum of the total intensity at $578 \mathrm{~K}$ on, the latter continuously diminishes and no additional volatile compounds are observed.

Temperature-Dependent FTIR Spectroscopy. The identity of the species evolved during the mass spectrometric experiments can best be probed by temperature-dependent gas-phase vibrational spectroscopy. To this end, an evacuated IR cell containing the powdered sample was heated to 740 $\mathrm{K}\left(1 \mathrm{~K} \mathrm{~min}^{-1}\right)$ while the range between 450 and $4000 \mathrm{~cm}^{-1}$ was scanned at intervals of 5-10 K. For clarity, the spectra obtained are shown in Figure 7 in the reverse order (back to front).

Around $363 \mathrm{~K}$, an asymmetric doublet in the nitrile region $\left(2260 \mathrm{~cm}^{-1}\right)$ rapidly gains intensity, which together with the absorption at 3550 and between 680 and $820 \mathrm{~cm}^{-1}$ can be assigned to isocyanic acid, $\mathrm{HNCO}{ }^{43}$ After reaching their maximum intensity around $413 \mathrm{~K}$, the bands have essentially disappeared by $453 \mathrm{~K}$. As observed by mass spectrometry, strong absorption due to ammonia emerges around $470 \mathrm{~K}$ and grows continuously up to the end of the measurements at $740 \mathrm{~K}$. Strong $\mathrm{NH}_{3}$ bands together with their well-resolved rotational sidebands are found at 929, 964, 1625, and 3333 $\mathrm{cm}^{-1}$. At the same time a broad band located around 2330 $\mathrm{cm}^{-1}$ and a weak band around $2970 \mathrm{~cm}^{-1}$, both being presumably due to $\mathrm{CO}_{2}$, increase. The simultaneous presence of the latter may result from the ongoing decomposition of $\mathrm{HNCO}$ at elevated temperatures by trace amounts of water, yielding $\mathrm{NH}_{3}$ and $\mathrm{CO}_{2}{ }^{43}$ However, at the end of the experiment a sublimation zone is visible, which has formed just outside the furnace. Besides melamine, a glassy substance and small white crystals were recovered, which by IR spectroscopy and powder X-ray diffractometry were identified as urea containing small amounts of X-ray amorphous material. Absorption around $2145 \mathrm{~cm}^{-1}$ in the IR spectrum can best be explained by traces of $\mathrm{NH}_{4} \mathrm{NCO}$, yet owing to weak additional absorption at $2255 \mathrm{~cm}^{-1}$, the presence of small amounts of sublimed starting material or cyanamide cannot be excluded. Thus, according to the expectations the simultaneous presence of $\mathrm{HNCO}$ and $\mathrm{NH}_{3}$ in a closed glass tube leads to the formation of urea via $\mathrm{NH}_{4}$ NCO. There is no evidence for the formation of other

(43) Fischer, G.; Geith, J.; Klapötke, T. M.; Krumm, B. Z. Naturforsch. 2002, B57, 19. 
Scheme 1. Tentative Reaction Pathways for the Formation of Melem from Guanylurea Dicyanamide ${ }^{a}$

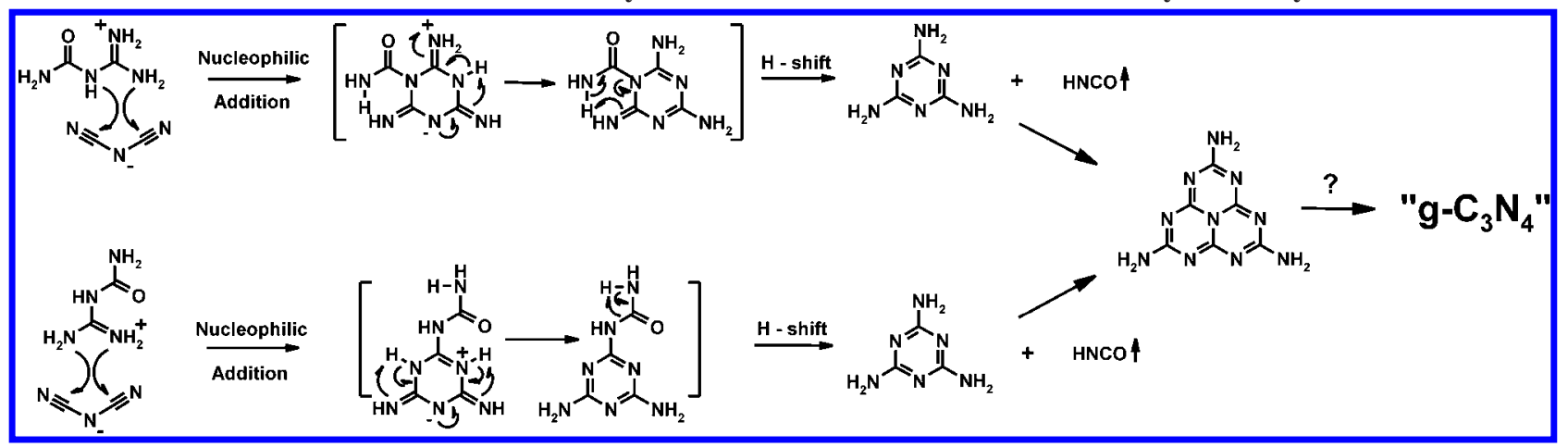

${ }^{a}$ In the top mechanism a nonaromatic intermediate is passed through, whereas the bottom pathway yields the stable ureidomelamine as an intermediate. After 1,3-H-shift and subsequent $\mathrm{HNCO}$ elimination melamine is formed as an intermediate product in both cases. Condensation yields graphitic $\mathrm{CN}_{x} \mathrm{H}_{y}$ material via melem.

decomposition products of $\mathrm{HNCO}$ such as biuret or cyanuric acid.

The differences in the relative intensities of the main species isocyanic acid and ammonia found for IR and mass spectrometry may be due to the intrinsic, nonquantitative sensitivity of IR spectroscopy for particular vibrations depending on symmetry considerations. In addition, the ongoing chemical decomposition of guanylurea dicyanamide is largely dependent on the pressure and temperature conditions, which are necessarily different for both analytical techniques. Thus, as will be discussed in the following, the condensation of melamine and, as a result, the amount of ammonia evaporated will be affected particularly strongly by the respective reaction conditions.

\section{Discussion}

As evidenced by the entirety of the temperature-programmed spectroscopic and diffraction experiments, the following conclusions concerning the thermal behavior of guanylurea dicyanamide may be drawn.

At temperatures around $373 \mathrm{~K}$ an exothermic transformation leads to the formation of melamine, the latter being detectable around $405 \mathrm{~K}$ by X-ray powder diffraction. Whether or not melting occurs prior to the decomposition reaction cannot be unambiguously resolved, yet visual inspection during sample decomposition in a sealed glass tube, as well as during the temperature-dependent spectroscopic experiments, strongly supports the solid-state character of the observed transformation process. However, the powder appears to sinter while being heated, adopting a sort of porous outer appearance.

Whereas the DSC measurements indicate two essentially exothermic events to accompany the formation of melamine, this two-step character is visible neither by $\mathrm{X}$-ray powder diffraction nor by the spectroscopic measurements.

In accordance with the results from temperature-dependent IR and mass spectrometry, the major thermal event around $390 \mathrm{~K}$ is most likely associated with the onset of HNCO formation, whereas the second exothermic signal may rather be due to the evaporation of ammonia or caused by structural changes owing to molecular reorientations or "recrystallization" of the sample from an intermediate amorphous stage.
Possibly, the decomposition or polymerization of the evolved HNCO may also give rise to the observed broad signal.

On the basis of the above experimental evidence, the microscopic mechanism of the melamine formation may be sketched as follows: Given the presence of nucleophilic and electrophilic sites carried by the molecular ions which are situated in close proximity within the crystalline structure, a cyclization reaction may proceed as depicted in Scheme 1. Two alternative ring closure reactions are possible, which owing to the guanidinium-like delocalized system of the cation are assumed to be very similar in terms of activation energy, both finally yielding melamine and $\mathrm{HNCO}$ in accordance with the above results. However, as may be seen from the proposed transition states, the top reaction pathway necessitates the passage of a nonaromatic intermediate, which is subsequently stabilized by facile elimination of $\mathrm{HNCO}$ via a six-membered cyclic transition state similar to a [1,5]sigmatropic rearrangement. The alternative pathway results in the formation of ureidomelamine ((4,6-diamino-1,3,5triazin-2-yl)-urea), which is known to be stable up to $T>$ $500 \mathrm{~K}^{44-48}$ Given the transformation into melamine proceeds at $T<450 \mathrm{~K}$, the top pathway seems to be clearly more realistic.

In general, the cyclization reaction follows a pattern analogous to that observed for the thermal conversion of both ammonium dicyanamide into dicyandiamide and guanidinium dicyanamide into melamine. Both transformations proceed via addition of the nucleophilic component (cation) after an initial proton transfer to the electrophile (anion), followed by a 1,3-H-shift and-in the case of guanidinium dicyanamide and presumably in the present case as well-a second nucleophilic addition leading to a ring closure reaction and subsequent proton rearrangement.

Cyclization taking place at the urea moiety of the cation would analogously yield ammeline (4,6-diamino-1,3,5-triazin-2(1H)-one, $\mathrm{C}_{3} \mathrm{~N}_{5} \mathrm{H}_{5} \mathrm{O}$ ) and cyanamide, $\mathrm{N} \equiv \mathrm{CNH}_{2}$, the latter of which is known to undergo trimerization, giving

(44) Oshima, Y.; Murata, A. Japanese Patent JP 42012429, 1967.

(45) D'Alelio, G. F. U.S. Patent US 2394042, 1946.

(46) Odo, K.; Ichikawa, S.; Yamashita, M. Japanese Patent JP 48064087 1973.

(47) Garrigue, R.; Lalo J. French Patent FR 2625198, 1989.

(48) Fingrhut, H.; Canzi, L.; Coufal, G.; Giacomuzzo, S.; Muellner, M. World Patent WO 9620183, 1996. 
melamine at temperatures around $443 \mathrm{~K} .{ }^{23,42}$ This pathway may occur to a small extent in a side reaction as indicated by the $m / z=42$ peak observed in the mass spectrometry experiments.

The evolution of ammonia at temperatures above $450 \mathrm{~K}$ can be correlated with the onset of melamine condensation, resulting directly or via the crystalline intermediate melem in the formation of amorphous $\mathrm{CN}_{x} \mathrm{H}_{y}$ condensation products. In addition, hydrolysis of $\mathrm{HNCO}$ also contributes to the evolution of ammonia, the amount of which is dependent on the reaction conditions and the presence of traces of water. It is assumed that, by conducting the reaction under vacuum, the equilibrium between melamine and its condensation products will be pushed to the latter side by enhancing the formation of volatile ammonia. Accordingly, the early onset of ammonia formation as detected by mass and IR spectroscopy and the production of relatively large amounts of amorphous $\mathrm{CN}_{x} \mathrm{H}_{y}$ phases can be explained. The yellow residue of the decomposition carried out in closed glass ampules at $743 \mathrm{~K}$ mainly consists of melem together with an unidentified crystalline side phase as well as graphitic $\mathrm{CN}_{x} \mathrm{H}_{y}$ material. Taking into account the elemental composition of melamine, which is isolated as a sublimate at the cold zone of the ampule, and the oxygen content of the residue, which amounts to $5.6 \mathrm{wt} \%$, indicates the initial oxygen content of the starting material (theoretically $9.5 \mathrm{wt}$ $\%)$ to be significantly reduced in the final product, although working in a closed system. Presumably, the generated $\mathrm{HNCO}$ partly decomposes irreversibly into $\mathrm{CO}_{2}$ and $\mathrm{NH}_{3}$ as described above. Thus, an "inert gas atmosphere" is produced which does not further affect or inhibit the formation of condensed $\mathrm{CN}_{x} \mathrm{H}_{y}$ phases. According to the above results, the formation of melem is favored in closed systems under $\mathrm{NH}_{3}$ back-pressure. In contrast, the evaporation of $\mathrm{HNCO}$ is supported when the reaction is conducted under vacuum, which however stimulates the uncontrolled condensation of melamine to amorphous hydrogen-containing carbon nitride materials. Thus, optimal conditions are given when working in "semiclosed" systems where pressure equalization is possible, as for instance in tightly filled glass capillaries used for XRD.

\section{Conclusion}

The thermal decomposition of the molecular salt guanylurea dicyanamide was followed by temperature-dependent diffraction and spectroscopic techniques. A synoptic view of the data presented above suggests the thermal transformation of guanylurea dicyanamide to yield the "prototype" $\mathrm{CN}_{x}$ precursors melamine and melem via addition and condensation reactions under concomitant evolution of HNCO and $\mathrm{NH}_{3}$. Therefore, another piece of evidence can be added with respect to the extremely facile formation of melamine at higher temperatures out of a range of related molecular $\mathrm{C}-\mathrm{N}-(\mathrm{O})$-containing systems, thus rendering melamine a "thermodynamic drain" in the constitution pathway of graphitic $\mathrm{C}_{3} \mathrm{~N}_{4}$ phases. The favored formation of melamine and subsequently melem as the only crystalline products may be of major relevance to synthetic approaches toward $\mathrm{CN}_{x}$ networks via the molecular precursor route. It clearly demonstrates the key role of the triazine and heptazine moieties as the ultimate prestages to $\mathrm{g}_{-} \mathrm{C}_{3} \mathrm{~N}_{4}$, even if the elemental stoichiometry of the starting material may differ substantially from that aspired for the condensation product. Special attention thus has to be paid to the presence of oxygen in the starting material, which is not integrated into the condensation product stoichiometrically and therefore does not substantially inhibit the formation of $\mathrm{CN}_{x}$ phases via melamine and melem. The suitability of such compounds as molecular $\mathrm{CN}_{x}$ precursors should therefore not be precluded automatically, but evaluated on the basis of their thermal reactivity. Hence, if outgassing of $\mathrm{HNCO}$ is allowed for by conducting the reaction under pressure equalization, the formation of $\mathrm{g}-\mathrm{C}_{3} \mathrm{~N}_{4}$ may be effectuated, though possibly at the expense of optimal crystallinity. This aspect may, for example, be utilized in the application of thin carbon nitride films on various substrates by dip-coating from ethanolic or aqueous solutions of the title compound with subsequent thermal decomposition.

In summary, this work is intended to draw attention to the potential suitability of oxygen-containing molecular materials, notably if facile $\mathrm{HNCO}$ formation is possible, for the synthesis of $\mathrm{CN}_{x}$ network materials.

Acknowledgment. We thank W. Wünschheim for conducting the DSC measurements as well as Dr. G. Fischer for his assistance with the mass spectrometry experiments. Financial support was granted by the Deutsche Forschungsgemeinschaft, the Fonds der Chemischen Industrie, and the BMBF (scholarship for B.V.L.), which is gratefully acknowledged.

Supporting Information Available: An X-ray crystallographic file (CIF) and tables of atomic coordinates, anisotropic displacement parameters, and bond lengths and angles for guanylurea dicyanamide (PDF). This material is available free of charge via the Internet at http://pubs.acs.org.

CM050350Q 